\title{
Correction to: Variations on intra-theoretical logical pluralism: internal versus external consequence
}

\section{Bogdan Dicher ${ }^{1}$}

\section{Correction to: Philos Stud https://doi.org/10.1007/s11098-018-1199-z}

In the original publication of the article, in Definition 4, the sixth line which reads as "(Monotonicity) if $X \vdash A$ and $X \supseteq Y$, then $Y \vdash A$ ";

Should read as "(Monotonicity) if $X \vdash A$ and $Y \supseteq X$, then $Y \vdash A$ ";

Publisher's Note Springer Nature remains neutral with regard to jurisdictional claims in published maps and institutional affiliations.

The original article can be found online at https://doi.org/10.1007/s11098-018-1199-z.

Bogdan Dicher

bdicher@me.com

1 Centre for Philosophy, University of Lisbon, Lisbon, Portugal 